\title{
ENTREVISTA COM FLÁVIA CÔRTES
}

Regina Michelli

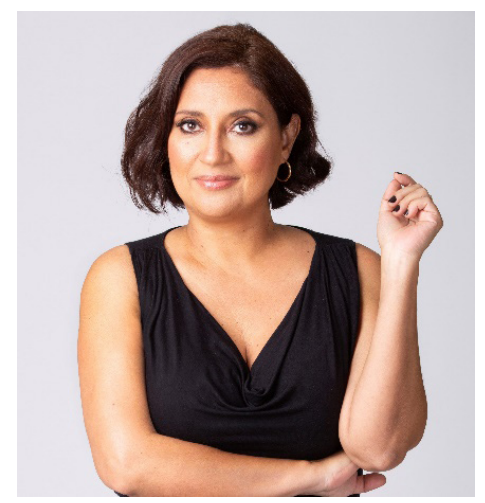

Flávia Côrtes é escritora brasileira, com uma produção de alta qualidade voltada para o público infantil e juvenil, ainda que suas obras não se restrinjam a esse público. Sua escrita transita da literatura infantil de fantasia à literatura juvenil, mergulhando principalmente no universo do fantástico, da ficção científica, das mitologias e do terror. Nascida na geração de 1970, época frutífera para a literatura infantojuvenil brasileira, é uma escritora que desponta no cenário nacional. Seu primeiro livro publicado, o infantil Medo de quê?, ilustrado por Ivan Zigg, rendeu-lhe diversos prêmios e seleções, como a da FNLIJ para representar o Brasil na exposição "A imagem do medo", da Galícia, Espanha, em 2006, e a do PNBE de 
2010; foi selecionado, em 2011, para os kits de leitura das prefeituras mineiras de Belo Horizonte e de Contagem e para o Programa Minha Biblioteca da SME-SP, em 2019. Suas obras se encontram publicadas por diversas editoras, como Cortes, Difusão Cultural do Livro, Biruta, Garamond, Jandaíra etc. Além do envolvimento com a atividade de criação literária, Flávia é roteirista, tradutora e integra uma geração de escritores de literatura infantojuvenil que busca o conhecimento acadêmico, cursando o doutorado em Estudos de Literatura na UERJ. A entrevista que aqui se traz versou sobre questões pertinentes não só ao seu universo profissional, como procurou abordar o ser feminino nesse cenário.

Com a palavra, Flávia Côrtes.

P.: Como é ser mulher, escritora e pesquisadora em um ambiente, até bem pouco tempo, dominado pelos homens?

R.: Em geral, o universo literário ainda é dominado pelos homens no Brasil, mas na literatura infantojuvenil (LIJ) as coisas não são bem assim. A LIJ brasileira se consolidou em Monteiro Lobato, no entanto, foram mulheres escritoras as responsáveis pela sua disseminação e permanência. São elas as grandes damas da literatura infantojuvenil brasileira: Ana Maria Machado, Ruth Rocha, Silvia Orthof, 
Lygia Bojunga Nunes, Marina Colassanti. Como mulher e escritora, sinto-me privilegiada por ter seguido os passos dessas autoras e chegado aonde cheguei. Tenho hoje 21 livros publicados, além de outros tantos como tradutora. Meus livros foram selecionados para diversos planos de leitura, como o PNBE, e adotados em muitas escolas por todo o país. Ao longo desses 15 anos de carreira, venho sendo convidada para diversos eventos e feiras literárias, dividi mesa com outros autores brasileiros para falar sobre a literatura infantil brasileira na feira do livro de Bolonha, na Itália.

Venho de uma família humilde, nasci e cresci em Bangu, subúrbio do Rio de Janeiro, e estudei em escolas públicas até o ensino médio. Meu pai foi o primeiro da família Côrtes a entrar para a universidade. Seguindo seus passos, entrei para a universidade pública, cursei Letras e especialização em LIJ na UFRJ, tornei-me mestre em Estudos Literários pela UERJ, e cheguei ao doutorado em Teoria da Literatura e Literatura Comparada na UERJ. Quem diria que aquela menina pobre chegaria tão longe? Embora eu sempre tenha acreditado, as chances eram restritas.

\section{P.: Como surgiram a escritora e a pesquisadora, o que se deu primeiro?}


R.: Considerando-se a pesquisa como um indagar de questões que inquietam, uma sede por buscar mais e mais conhecimento, as duas surgiram ao mesmo tempo. Escrevo desde os 6 anos de idade e desde essa época tenho grande curiosidade sobre muitos assuntos, que vaga de um interesse a outro e de tempos em tempos. Embora a literatura seja o que mais me atraia - vivo investigando a escrita do outro, lendo o mais que posso para me manter atualizada e abastecida de ideias -, alguns outros temas me encantam. Mitologias, por exemplo, grega, celta, egípcia, todas me fascinam. Muitas dessas leituras e pesquisas acabam virando temas de meus livros.

A pesquisadora, no entanto, surgiu um pouco mais tarde. Como escritora, senti uma necessidade cada vez mais crescente de conhecer a fundo a literatura, a teoria por trás da arte. Meu maior interesse recai sobre a literatura infantojuvenil brasileira contemporânea. No mestrado, trabalhei com a literatura infantil como agente formador de leitores críticos em sala de aula e, no doutorado, sobre como o maravilhoso é revisitado por autores brasileiros na última década de 2010, 2020.

\section{P.: A pesquisadora influencia a escritora e vice-versa?}


R.: Acho difícil dissociar as duas e certamente influenciam-se mutuamente. Minha dissertação de mestrado, por exemplo, teve um tom mais leve que a maioria das pesquisas acadêmicas. Em alguns momentos tive dúvida, sobre se mantinha a narrativa daquela forma, mas fui incentivada pela minha orientadora, Regina Michelli, grande referência nas pesquisas sobre o maravilhoso e sobre a literatura infantojuvenil, de quem sou grande admiradora.

Mas a pesquisadora também influencia a escritora. Não sou capaz de escrever um texto que dialogue de alguma forma com um conto de fadas, por exemplo, e não pensar nos grandes nomes, fundadores do gênero, como Basile, Perrault e os irmãos Grimm.

P.: Recentemente saiu uma matéria grande no jornal $\boldsymbol{A}$ tribuna sobre sua obra. Como é ver seu nome estampado em jornais e revistas?

R.: Acredito ser consequência positiva de um longo trabalho. Venho me dedicando à escrita há muito tempo e busco cada vez mais me aprimorar como escritora. A mídia é sempre uma boa aliada e é gratificante ver o meu trabalho reconhecido. Por ocasião de seu lançamento, meu livro Medo de quê? entrou para a lista dos 30 
melhores livros do ano da Revista Crescer, e isso me deu um bom destaque perante alguns editores. Em um meio em que quem compra o livro não é o leitor, e sim o responsável adulto, é muito importante essa divulgação. Como escritora, já fui entrevistada em alguns programas de TV, como o ABZ do Ziraldo, o RJ TV, o Alternativa Saúde e o Rede Escola.

P.: Seu nome tem aparecido na imprensa recentemente por outro motivo além dos livros. Em 2021 irá estrear um filme infantojuvenil roteirizado por você, o De folha em flor. Como foi migrar para esse universo cinematográfico?

R.: Trabalho com roteiro há anos e colaborei em alguns. Esse será o meu primeiro filme a ir para as telas, mas não escrevi o roteiro sozinha. Foi uma parceria com o roteirista e diretor Francisco Malta. Eu e Chico nos conhecemos há 15 anos no curso de roteiro televisivo da dramaturga Leila Míccolis, e nos tornamos amigos, escrevemos juntos desde então. Temos outros projetos prontos, aguardando lançamento. De folha em flor é um telefilme inspirado em um livro meu de poemas para crianças, já fora de catálogo, e tem previsão de lançamento para o segundo semestre de 2021, pelas plataformas de streaming Now, Looke, Claro TV e Vivo Play. A direção é de Luan Moreno, 
e a produção, da agência Cintra. Temos ainda um elenco de peso, com Babi Xavier, Anja Bittencourt, Sávio Moll, entre outros.

P.: Já encontrou alguma dificuldade em publicar um livro pelo fato de ser mulher?

R.: Acredito que sim. Um dos temas que me atrai é a ficção científica e esse é um nicho muito fechado no Brasil, ainda dominado por autores do sexo masculino. Algumas mulheres se destacam, como Ana Cristina Rodrigues, Finisia Fideli e Simone Saueressig, mas ainda são poucas. Tenho vários textos com essa temática, mas somente um livro publicado, $O$ segredo das borboletas, um romance juvenil sobre viagem no tempo. O título remete ao "efeito borboleta", uma teoria da física.

R.: A obra $\boldsymbol{O}$ segredo das borboletas trata de um grupo de jovens que, diante de uma série de desastres ambientais, viaja no tempo a fim de salvar o planeta. 0 livro fala ainda da colaboração do Brasil nas pesquisas espaciais, em especial no lançamento de satélites de observação climática. Como foi escrever sobre algo tão específico, exigiu muita pesquisa?

R.: Em geral, quando o tema permite, sempre parto da pesquisa para a construção do universo ficcional. Esse livro 
exigiu bastante de mim, precisei pesquisar bastante sobre vários assuntos, como sobre a colaboração do COPPE da UFRJ com outros países, para o desenvolvimento de satélites climáticos. Tive ainda que aprender o máximo possível sobre o Alzeimer, já que uma das personagens apresentava essa doença. Muitos dos meus livros foram criados dessa forma. O processo de aprofundar meus conhecimentos sobre algo, a fim de criar verossimilhança para a trama, me atrai muito.

P.: Em sua opinião, existe uma divisão do mercado literário entre o que seria uma literatura feminina e uma masculina?

R.: Talvez de forma velada. É o que acontece na ficção científica e na literatura policial. Conheço grandes escritoras, com carreiras consolidadas, que têm dificuldade para publicar esses temas. Por outro lado, já fui convidada algumas vezes para escrever chick lit e acredito que o convite tenha sido feito por eu ser mulher. Não é uma literatura que me atraia, não sou leitora do gênero e por isso não aceitei.

Existe, sim, uma escrita estritamente feminina, feita por mulheres e direcionada a mulheres. Mas existe também o outro lado. No universo da ficção científica, por exemplo, 
é recorrente a representação de personagens femininas de maneira extremamente sensual e sexista. Contudo, entre meus amigos escritores, há homens que escrevem chick lit e mulheres que mergulham na ficção científica e no romance policial. Na minha opinião, essa diferenciação não deveria existir. O que mais importa é um escritor ser livre para criar aquilo que quiser.

\section{R.: Se fosse destacar um único livro de sua trajetória, qual seria e por quê?}

R.: Curioso é que a pergunta mais ouvida por mim nas escolas e em feiras literárias é de qual livro gosto mais, dentre os que escrevi. Isso não acontece só comigo. Essa é a pergunta mais ouvida pelos escritores brasileiros de literatura infantil e juvenil. A resposta de praxe é que livro é como um filho, gostamos de todos. Mas isso não é bem verdade. Acredito que todos nós temos os nossos preferidos.

Dos meus livros publicados, tenho um carinho muito especial pelo Pra voar mais alto. Trata-se de um livro sobre perdas e superação, sobre um menino que tentava manter a memória do pai falecido enquanto lidava com o novo namorado da mãe. Esse foi um livro que me arrebatou em muitos sentidos, que me desafiou, e que, nas muitas reescritas que fiz, me tornou não só uma escritora melhor, 
mas uma pessoa melhor. Ele me fez rir e me levou às lágrimas muitas vezes durante o processo. É um livro que fala de saudades e mexeu muito com algumas de minhas memórias familiares. Esse livro recebeu uma menção honrosa do Creativity International Awards e foi escolhido para fazer parte do conceituado catálogo da feira do livro de Bolonha, na Itália.

P.: Qual a relevância de imprimir a sua voz a uma literatura voltada para crianças e jovens?

R.: Não tenho a pretensão de influenciar ninguém para nada com a minha escrita. Tenho aversão ao didatismo, ao moralismo, à ideia de passar uma mensagem formada para o leitor. O que pretendo, isso sim, é formar leitores, o mais críticos possíveis. Tocar o leitor em seu íntimo, levá-lo a refletir sobre a vida, sobre si mesmo, sobre o outro, fazê-lo sentir como eu me senti ao escrever aquele texto. No fundo, no fundo, o que mais quero mesmo é encantar o leitor.

\section{P.: O que diria para uma mulher que esteja começando a} vida como escritora?

R.: O mesmo que diria a qualquer outra pessoa: Leia muito, leia sempre. A boa escritora não pode existir sem antes ter sido uma leitora crítica. Conheça bem o 
que está sendo publicado em sua área de interesse literatura infantil, juvenil, poesia etc. Não adianta querer ser escritora de literatura infantil e não ler literatura infantil, não conhecer o que é qualidade na área. Observe o que está sendo premiado, quais títulos mais vendem, quais autores se destacam. Frequente as feiras e os eventos literários. E escreva sempre. Escrever é um exercício e exige muita dedicação. Conheça as técnicas de construção de texto, leia livros teóricos. Mas, acima de tudo, acredite em si mesma. Uma hora seu esforço será recompensado.

Regina Michelli é professora associada da Universidade do Estado do Rio de Janeiro (UERJ), em regime de D.E., atuando na Graduação e na Pósgraduação em Literatura Portuguesa, Teoria da Literatura e Literatura Comparada. É pós-doutora em Letras Clássicas e Vernáculas pela USP (2014) e atualmente encontra-se em estágio pós-doutoral na UFU, ambas as pesquisas em torno da Literatura Infantojuvenil, abarcando estudos sobre contos de fadas, identidades de gênero, maravilhoso e insólito em narrativas da tradição e da contemporaneidade. É líder, juntamente com o Professor José Nicolau Gregorin Filho, da USP, do Grupo de Pesquisa do CNPq EnLIJ - Encontros com a Literatura Infantil/ Juvenil: ficção, teorias e práticas; participa do Grupo de Trabalho da ANPOLL Vertentes do Insólito Ficcional e coordena o Núcleo de Estudos em Literatura Infantojuvenil da UERJ (NELIJ-UERJ). 